\title{
Economic analysis of new rural cooperative medical service financing model based on environment perspective
}

\author{
Chang Liu ${ }^{1}$, Huaisheng $\mathrm{Li}^{2,}$, , and Shanxing $\mathrm{Luo}^{3}$ \\ ${ }^{1}$ School of Health Management, Hangzhou Normal University, Hangzhou, China \\ ${ }^{2}$ Hangzhou Yi-Ning Hospital, Hangzhou, China \\ ${ }^{3}$ Taierton Economic Studies \& Consulting Center, Hangzhou, China
}

\begin{abstract}
The purpose of this paper is to continuously to improve health security benefit of China's New Rural Cooperative Medical System (CNRCMS). In the light of consumer's choice theory and life-cycle theory, from the perspective of cost, efficiency and utility, this paper analyses the health effects of the typical financing models in different environments. The results show that different environmental conditions are significantly related to the adaptability of the rural social and economic development level to the fund-raising model. The conclusion is that improving the environment and establishing multiple health insurance mode are of great significance to reduce the financing cost and improve the health status of the CNRCMS.
\end{abstract}

\section{Introduction}

China's new rural cooperative medical system (CNRCMS) has the nature of public goods supply and market characteristics, it is organized, guided and supported by government, and is financed by individual, collective and government, and is the medical system of mutual-aid to a serious illness as a whole. However, due to the existence of the utility of health consumption, CNRCMS is of great cost, and the waste of health resources is serious during the implementation process. This may be closely related to the harsh environment in China's rural areas. As far as population health and welfare are concerned, the urban and rural human settlements should be objective, and the difference between the two should only be the completeness of public facilities and environmental reform in the course of development. It is mentioned the individual perception on external factor strength to be influenced by level of easiness or difficulty that the attitude and behavior appear [1].

Moreover, farmers' awareness of environmental protection has been greatly reduced because of the lack of awareness of the health care needs of farmers and one of their CNRCMS. According to the theory of commodity supply and demand, farmers' demand for medical services tired at the same time, lack of medical and health supplies also existed, the results will be compared with the harsh environmental factors together to the farmers' health care and the quality of the labor force have a negative impact. And the health education of farmers, the construction of medical facilities, the organization and management of institutions need to invest huge sums of money, and the investment in environmental improvement is much less. As the asymmetric information about product or service is a salient feature of the medical market, farmers as service subject is often in a weak position in the medical consumer choice. This situation is the cause of the medical service market in the allocation of resources cannot be achieved in a fair and efficient. The choice of medical services consumption is different from general goods or service, it is mainly determined by the individual vital signs and the cultural environment, nobody is willing to get the benefits from the cost of disease in CNRCMS (i.e., medical utility), and shows the characteristics of passive choice of medical consumption. And the profit margins are very limited for the basic medical service providers in the current market, particularly in economically underdeveloped areas. Meanwhile, the unfair competition between interest subjects causes widely result in wasting of health resources. So, government functions more importantly are to standardize market behavior from the perspective of macroeconomic regulation and control, in addition to directly participate the investment in CNRCMS to promote the formation and development of a low cost and high efficiency financing model.

\section{The farmers consumption choice of CNRCMS medical service}

In recent years, farmers' medical burden has been reduced slightly, medical demand is gradually increased. However, in the practice of CNRCMS, the medical supply and demand can't realize the relative balance,

*Corresponding author: hzsflc@163.com 
rising medical costs also generally exist, it causes the new rural cooperative fund gap and the difficulty of funding continues to increase. the irrational phenomenon of current rural consumption structure is becoming more and more serious, the backward mode of funding is more difficult to meet the health needs of China's farmers. Studies suggest that rational consumption can effectively increase farmers' health stock [2]. By integrating environment, health and safety (EH\&S) Management System, Hiwa Hossaini al. (2015) used a new approach with a systematic, creative, and cultural context to explain the interaction between health, safety, and the environment [3].

Aiming at these issues, much of the research on CNRCMS is focused on the behavior and service mode of medical providers, and the researchers think the only way to control the medical expenditure is to change the behavior of the supplier. While the demand for farmers' health care is focused on its price elasticity and its influencing factors. Wang \& Rosenman (2007) found that education, income, family size and other significantly impacts had a significant impact on individual medical needs and costs through the investigation of rural medical needs in Ningxia and Zhejiang [4]. Most of the similar conclusions are based on the assumption that farmers have sufficient health knowledge. And in fact, farmers lack of health awareness, medical consumption selectivity is poor, especially affected by the rural development level, living habits and medical consumption characteristics and other factors. Based on the data of CHNS in 1991 and 1997, Feng Jin, al. (2006) showed that the income elasticity of farmers' medical expenses was 0.35 , which was in the low demand income elasticity in the health industrial market [5]. Wang Weizhong (2008) investigated the demand elasticity of medical demand using its price or income function [6]. Some similar studies have indicated that different gender, age, income level and health status of the rural population have different price elasticity of medical demand. The common influencing factors include: personal characteristics, work environment, social and economic conditions [7]. These factors have a direct impact on the health of farmers, so as to determine their health consumption awareness. Xin Gu's (2006) special research on the new rural cooperative financing showed that farmer's participation was not the key ability to pay but willingness to participate [8]. But there is no further explanation from the perspective of economics to explain the impact of farmers' willingness to participate in the deep reasons. A lot of research that deductible, reimbursement and cap lines design is too harsh, affecting the farmers basic medical security level, so then blow to the enthusiasm of farmer participation. Wei Zhong (2004) used the data of China Nutrition and Health Survey in 1993 to explore the influence of Chinese peasants' health on employment and wage, and tried to reveal the relationship between health needs and income of farmers from the micro-level [9]. But if the needs of the main consumer initiative study is ignored, it may increase the difficulty of financing, and even lose the ability to control cost and system defects caused by CNRCMS. In fact, the key to raising funds for the new rural cooperative medical system lies in the lack or distortion of the farmer's health consciousness, directly lead to farmers cannot balance the positive relationship between health care spending and health, and emerge confusion in the choice of health consumption, health insurance spending too low or the proportion of imbalance. Health resource allocation efficiency was reduced, which further reduced the allocation efficiency of health resource.

In the free competitive market, the commodity and its trading main body have information transparency enough to reduce the transaction cost as far as possible. The information asymmetry makes farmers produce adverse selection and moral hazard in the process of medical service, and reduce the utility of health resources fundamentally. Although the characteristics of social medical insurance compulsory insurance effectively prevent the adverse selection, but some medical institutions also often appear moral hazard, causing varying degrees of damage to farmers' interests and market failure. When the demand for medical service is lower than the price of the service, the behavior will be distorted, which lead to the abuse of medical resources. This will increase the operation cost of CNRCMS, and put forward higher requirements for the number of financing, ways and technology. In addition, lack of fund of CNRCMS determines the participation of farmers in the basic medical service are entitled to the compensation range and proportion limitations, resulting in its low payment rate of return. Therefore, the selection of consumption demand body (farmers) source the influence on social factors, the medical needs of farmers, psychological factors, technical factors and rural medical security mechanism.

\section{The impact of the health status of farmers and medical expenditure on funding}

\subsection{Health and medical expenses determine the cost of funding}

The total cost of funding reflects the rural medical expenditure and the health of farmers, and is restricted by the number of agricultural populations, resource utilization and social management in a specific area. In recent decades, more than once, human beings have been faced with the risk of disease transmitted by pathogenic microorganisms through sewage [10]. The effective control of sewage and other environmental improvements in health pathways has attracted wide attention in the international community. And the per person funding cost does not exist in this area, so it can reflect the change of the cost and benefit of the fund raising. In 2003 the fund-raising cost was quite high, 5.53 RMB, since the implementation of CNRCMS, the per capital funding costs declined year by year. Although there were slight fluctuations from the beginning of 2005 , but the overall trend was still showing a downward trend in 2009 per capital funding costs fell to 1.54 RMB, 
compared with 2003 decreased by nearly 4 RMB. The reduction of the cost of raising funds and the increase of investment have effectively promoted the improvement of the health level of the farmers.

However, there are still some problems of farmers' self-funding part to charge in many rural. The relevant department staff in some places need to finance door-to-door, and fund management technology is relatively backward, this result in high self- funding cost. In the history of China, there were all kinds of unreasonable charges in the name of cooperation, which led to some farmers' rebellious psychology towards the CNRCMS funding and propaganda, and increased the difficulty of subsidy. This situation caused by the low efficiency of the collection and use of funds. At present many funds of CNRCMS are borne by specialized cooperative medical institutions and their operation requires a considerable cost. The use of funds is lack of adequate supervision, and there are a lot of waste phenomenon, or even fund fraud phenomena. If we do not use the multi-channel health promotion mechanism, it is not conducive to the production, accumulation and utilization of health benefits of farmers, and affect the sustainable development of China rural social and economic development. In economics, health production function summarizes the relationship between health status and various factors that influence health. It is generally used in medical treatment, non-health care investment and time to produce health.

$$
\text { Health }=H\left(m_{s}, h_{\text {inv }}, t\right)
$$

Among them, Health means health status, $m_{s}$ means health care, $h_{i n v}$ means the investment in non -health care, $t$ means the treatment of disease and maintenance of health in the time spent. Health care spending is not the only means to improve health; other factors that affect health, such as lifestyle, environmental pollution and health industry development, will change the overall health yield curve (see Figure 1). A large number of motor vehicle exhaust and air pollution caused by the current haze will increase the regional population of respiratory diseases, infectious diseases may make people's health is threatened, thereby increasing the awareness of health risks. On the contrary, good living habits, scientific diet and proper exercise will improve the health condition, reduce the total demand of medical insurance fund and financing pressure. The implementation of the village planning, family health, drinking water sanitation and health of livestock and poultry in many rural areas, improve garbage and sewage treatment, road hardening, greening and beautifying the environment sanitation construction can not only ensure the health of farmers, will also promote the sustainable development of rural economy and society. This will play an active role in protecting and developing the rural labor force and improving the health quality of the population.

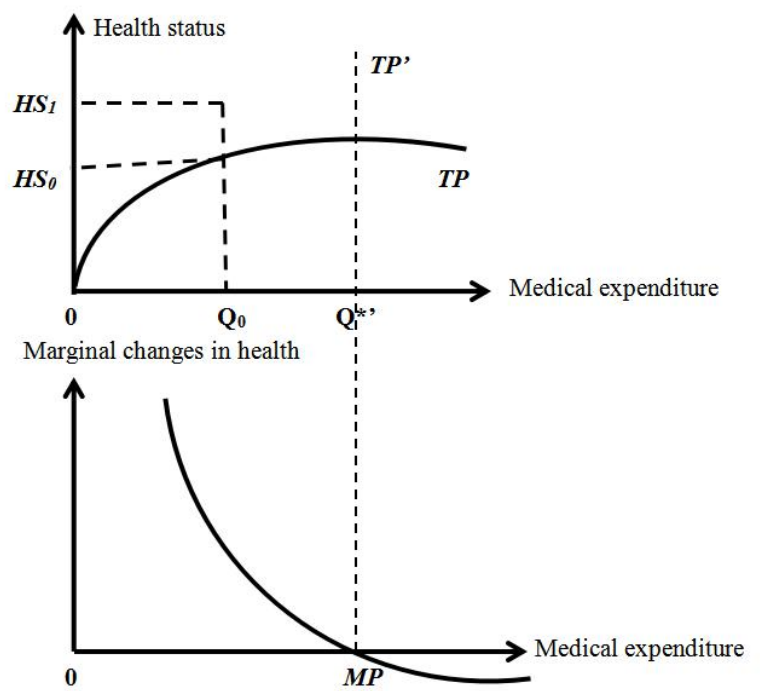

Figure 1. Marginal changes in health care expenditure

At every level of medical expenditure and improving these factors will form a better health status and curve is used to represent the production function from $\boldsymbol{T P}$ moved to $\boldsymbol{T P}^{\prime}$. To set the production function is the maximum health status of a given level of medical expenditure. If a person medical costs for $Q_{0}$, affecting the health of other factors unchanged, can achieve the maximum health for $H S_{0}$. Improving the health status of the two obvious methods: one is spending more money on medical expenditure, in static health production function $\boldsymbol{T P}$ move to greater heights, to financing put forward higher requirements; or lifestyle changes, this curve to move to $\boldsymbol{T} \boldsymbol{P}^{\prime}$, which is to establish a healthy and diverse security system, reduce medical expenditure, so that the financing pressure and the decrease in cost. Spending more on high - level health care costs will not improve health, since the curve is flat. However, no increase of medical expenses, $H S_{l}$ can still be obtained through lifestyle changes, such as, science, diet, exercise and relieve pressure. When the level of medical expenditure is greater than $\mathrm{Q}^{*}$ (indicates the critical point of medical expenditure), the slope of the health production function is negative; beyond that point, the increase of expenditure will not promote health improvement, but may have a negative effect on health. Although on the whole society, is unlikely to encounter this, but personally, this is the existence of, drug side-effects and misdiagnosis of destruction of normal life activities, is overuse of health care to patients by pure damage and waste of resources. According to the theory of consumer choice, people is always based on their own needs and the social and economic culture, compare the interests of goods or services for free and rational choice of consumption. A fully competitive market can reduce or eliminate the information superiority of product provider in terms of product cost, quality and pricing, so that consumer surplus and producer surplus distribution is more reasonable. In view of this, the reasonable health consumption of farmers is conducive to improving the efficiency of health care, which may reduce the unnecessary cost of funding. 


\subsection{Model analysis of funding cost}

Due to the lack of effective demand, medical services in improving the health of farmers there is a huge space, but it is difficult to estimate accurately health benefits, it can't allow farmers to give greater expectations of CNRCMS. The combined effects of backward culture, lifestyle and environmental factors, especially individual differences, causes the medical service impact on the health of farmers is difficult to peel, measure the marginal revenue to pay a high cost. Therefore, the increase of basic preventive health care investment in order to effectively improve the health benefits of farmers.

Adverse selection in CNRCMS funding process is inevitable, the strong healthy persons with higher income and the ability to pay, they expect low income, so the desired low. Assuming that the market only by a monopoly in the two parts of the insurance institutions and private consumption, insurance agencies chase profit maximization $\pi$, and the subject of insurance needs to avoid the risk of consumption.

Assuming that farmers do not fall ill, their income is $I$, when the income becomes $I-d, d$ means the loss of farmers sick, where the probability of illness assumed $p$. If farmers participate, they need to pay fees $a_{1}$, when they are sick, they can get compensation for $\mathrm{a}_{2}$.

But when the farmers participate and don't get sick, their income is $I-\alpha_{1}$, if they are sick, the income is $I-\alpha_{1}+$ $\alpha_{2}$. Set $\left(\alpha_{1}, \alpha_{2}\right)$ for the insurance contract, for the study of different farmers disease risk and willingness to medical treatment, here were used $\mathrm{p}^{\mathrm{i}}$ and $\gamma^{\mathrm{i}}$ means the farmer's illness probability and sickness after the doctor will; of which, $i$ equals $\mathrm{H}$ (high), $\mathrm{L}$ (low). And the set $d=d_{0}+r C_{0}$, which, ${ }^{d_{0}}$ means farmers due to illness of fixed loss, such as bodily injury and delays; $C_{0}$ means medical farmers pay for the medical expenses, due to the presence of participating farmers usually only in the designated medical institutions medical treatment and relatively stable medical accessibility. Therefore, we cannot consider the farmers' choice of different levels of medical care under the condition of constant medical costs; with parameter $\mathrm{r}$ epsilon $r \in[0,1]$, medical treatment will $\gamma=0$ means reluctant to seek medical treatment; $\gamma=1$ means must go to a doctor. In addition, if the insurance agency provides a variety of contracts, the contract can be expressed as $\mathrm{Ci}=\left(\alpha_{2}^{i} \alpha_{1}^{\mathrm{i}}\right)$, where $i=\mathrm{H}^{\prime} \mathrm{H}$ (high), L (low). This contract as a link of the funding model is embodied in the interests of both parties in the game. So that when farmers do not fall ill, the income is for the $\mathrm{I}_{1}$, sick for the $\mathrm{I}_{2}$, by the above assumptions, it can get the farmer's expectations of CNRCMS.

$V\left(p, \alpha_{1}, \alpha_{2}\right)=(1-p) U\left(I_{1}\right)+p U\left(I_{2}\right)$

Due to the assumption that farmers are risk averse, so $U \geq 0, U^{\prime \prime} \leq 0$ 'i. Good health or lack of health knowledge will enable farmers to participation, and bring the loss of bias, the expected utility of farmers not participating as:
$V\left(p^{i}, 0,0 \mid C_{0}, \gamma^{i}\right)=\left(1-p^{i}\right) U(I)+p^{i} U\left(I-d_{0}-r^{i} C_{0}\right)$

And participation of farmers mainly for avoiding health risk and disease of medical compensation, some farmers tend to new rural cooperative medical care utility, participation of farmers expectation utility:

$$
V\left(p^{i}, \alpha_{2}^{i} \alpha_{1}^{\mathrm{i}}, \alpha_{2}^{i} \mid C_{0}, \gamma^{i}\right)=\left(1-p^{i}\right) U\left(I-\alpha_{1}^{i}\right)+p^{i} U\left(I-d_{0}-r^{i} C_{0}+\alpha_{2}^{i}\right)
$$

The conditions for participating farmers:

$$
V\left(p^{i}, \quad \alpha_{2}^{i} \alpha_{1}^{\mathrm{i}} \mid C_{0}, r^{i}\right) \geq V\left(p^{i}, 0,0 \mid C_{0}, r^{i}\right)
$$

We examine two cases of different farmers' risk of disease and willingness to medical treatment, the focus of the disease risk, and it is assumed that the doctor will agree, and then analyze the willingness of medical treatment is different and the same disease risk. The funding level of participation of farmers mainly by farmers and decision for your own health and medical, and disease risk is key factor. If you only consider the risk of disease $p^{i}$ is different, but $\gamma^{i}$ as a constant $\gamma^{0}$, here farmers insured conditions:

$V\left(p^{i}, \alpha_{2}^{i} \alpha_{1}^{\mathrm{i}} \mid C_{0}, r^{i}\right) \geq V\left(p^{i}, 0,0 \mid C_{0}, r^{i}\right)$, that is:

$\left(1-p^{i}\right) U\left(I-\alpha_{1}^{i}\right)+p^{i} U\left(I-d_{0}-r^{i} C_{0}+\alpha_{2}^{i}\right) \geq\left(1-p^{i}\right) U(I)+p^{i} U(I-$ $\left.d_{0-} r^{i} C_{0}\right)$

Available $p^{i} \alpha_{2}^{i}-\left(1-p^{i}\right) \alpha_{1}^{i} \geq 0, \quad$ and when $p^{i} \alpha_{2}^{i}$ - (1$\left.p^{i}\right) \quad \alpha_{1}^{i}=0$, the profits of insurance institutions is maximized. And insurance institutions for the risk of diseases of each type of farmers, its profit is:

$\pi^{\mathrm{i}}=-\alpha_{1}^{i} \quad p^{i} \alpha_{2}^{i}=p^{i} \alpha_{2}^{i}+\left(1-p^{i}\right) \alpha_{1}^{i}$

But insurance institutions total profit depends on the number of units insurer profits and participation of farmers, reasonable fiscal investment makes the participation rate maximum and the farmers health benefits coverage, it would be insurance mechanism of raising maximum number of profits.

\section{Government function analysis of new rural cooperative medical system}

The proportion of funding accounted for government subsidies is an important factor affecting the level of CNRCMS funding. The improvement of funding criteria can further increase government investment, expand the scope of protection, be benefit to more farmers, the financing difficulty and the cost can be reduced through policy guidance and health promotion. The government function is to eliminate the concerns of farmers to CNRCMS, and guide farmers to establish health awareness and health attitude.

The government should inject capital into CNRCMS through mandatory tax policy or social medical assistance guide, realize the maximization of social welfare, establish and improve the long-term mechanism of government health survey and the fiscal subsidy, and clarify the investigation, evaluation and supervision responsibilities of finance at all levels. To a certain 
extent, the government expenditure structure will be transferred to the rural social security, especially to the rural poor. And gradually increase the proportion of funds to support CNRCM, so as to ensure a stable source of funding for CNRCM. The central government subsidies and local real economic conditions combined to effectively play the use of funds. Secondly, according to the local economic level and the level of medical expenses, appropriately increase the amount of individual. According to the research on the CNRCM in China, the reasonable proportion of farmers' per capita net income should be $1 \%$ to $2 \%$. In addition, you can also through other way to broaden the funding channels, guide the social from all walks of life to contribute to CNRCM, the change of financing structure, reduce financing risk, increase total financing, so that the majority of participating farmers really benefit [11].

On the road of the reform of the medical market, the government should strengthen the market supervision. Irrational use of drugs and the frequent repetition of the physical examination and other resources to waste phenomenon is more prominent, offset by the utility from farmers in new rural cooperative medical system by rising medical costs and side effects without real benefits, and produce negative psychological effects [12]. In addition, due to the country to implement the same amount of subsidy law, that is to give the same number of local grants, increased the difficulty of financing the backward areas.

\section{Multiple health benefits need to reduce CNRCM's funding}

\subsection{The cost and benefit of CNRCM}

The farmers' participation economic decision-making must follow the marginal cost equals the marginal benefit of the basic principles of microeconomics. The decision-making in actual life surely may have the deviated situation, but are often contrary to the true wishes. Most of farmers focus on the current interests, they rarely take into account CNRCM's health risk and income growth which may produce in the future. With the improvement of living standards, most farmers would from medical insurance gradually shifted to preventive health care demand for diverse health, and may reduce the dependence of the new rural cooperative medical service, so as to reduce the difficulty and amount of financing. The social insurance institutions established by the government for the social medical insurance shall handle the insurance, and then provide the medical services to the insured by the medical institutions. If the government does not provide public health services for farmers, the costs incurred by the medical services are borne by the private sector. One is to participate in commercial insurance, which costs more and only pays attention to a few high-income groups; the other is to participate in CNRCM voluntarily in private. In resolving medical service funding problems, it is generally in a low-level range, and it is difficult to achieve unity of costs and benefits. The farmers individual income level get gradually improvement and there awareness of risk has been increasing, so that more farmers are willing to reduce the risk of disease through insurance. At this time, the efficiency of CNRCM's insurance will be increased with the increase of income, and may be transferred to more healthy consumption to achieve a new balance of cost and benefit. This approach is mainly based on the non-active consumer choice of the market, but also requires the insurance agencies to actively guide the insured person to participate in health care activities, in order to reduce the cost of services.

\subsection{The CNRCM's funding mode under multiple health needs}

Multiple health needs have a significant impact on to improving the farmers' health [13], and reduce the cost of medical insurance. The empirical research indicates that good health is beneficial to increase the income of farmers, reduce the financing difficulty.

In China's rural areas, the government needs to implement its own funding responsibility, give full play to complementary role of collective economy. Encouraging enterprises and other business entities increase investment on farmers' health through the social responsibility of industry nurturing agriculture, actively guides the social from all walks of life to the farmers' health insurance contributions, and establishes voluntary contribution mechanism of convenient, flexible and efficient in rural areas where conditions permit. Through the analysis of existing data, it is found that the different modes of funding in the CNRCM efficiency first in the economic and social development faster region mainly for cost, funding efficiency is high, the farmer's strong support intensity, the security of fund and financing higher satisfaction [14]. Secondly, the efficiency of rolling mode of financing is low, the third is the higher cost of door-to-door collecting model, and the indexes are all low. The research group investigated the rural areas in Hangzhou, Shanghai, Guangzhou, Harbin, Taizhou and other places, and found that farmers around the way to raise funds for a variety of general trust; basic trust and the proportion of very trust is as high as $93.2 \%$. Due to the rolling mode of financing for the reimbursement of funds directly into account, farmers of the trust is the highest, the survey found, sample of the area time, there are some differences in the fund raising, funding the least time to about half a month; village cadres door-to-door collection fund raising time is relatively long, a month or even longer time, rolling financing is the year as long as the reimbursement of medical expenses of farmers can be regarded as the payment of a fee. In addition, in an interview with the relevant grass-roots managers generally reflect the implementation of the financing policy, there is a long time to implement the problem, but with the improvement of the policy, the efficiency of financing is gradually improving.

Regardless of the mode of funding is widely carried out multiple health care area, the health needs of the majority of the farmers are satisfied, their demand for 
medical services is significantly reduced, thus under the guarantee of basic health conditions, effectively reduced CNRCM funding levels and cost.

\section{Summary and recommendations}

Due to the lack of designated medical institutions and other reasons, the majority of farmers in the new rural cooperative medical system under the accessibility and low, health consumption choices are limited, thus increasing the cost of financing. At the same time, a variety of prevention and health care consumption has not formed a large market in the countryside, farmers demand for medical service dependence on a single, it is difficult to in the short term change an enormous pressure on medical expenditure, thus further increasing the funding difficulty. To solve the problems faced by the current stage of the new rural cooperative medical system, it is recommended to focus on the following three points:

\subsection{Increase the efficiency of rural basic medical services}

Government should within the framework of the existing system of referral, remote medical treatment and compensation to make specific provisions, participation of farmers rights protection, convenient medical treatment and compensation; and will the country in line with the conditions of primary level medical and health care institutions are included in the scope of designated medical institutions. Governments at all levels to strengthen the construction of primary health care institutions and personnel training, and constantly improve the quality of service and efficiency of designated medical institutions, so that reasonable examination and treatment, rational use of drugs, control of medical expenses. At the same time, the government should establish multi supply system according to the specific economic attributes of different rural public service environment, introduction of environmental protection in the supply of public services in rural health infrastructure competition mechanism.

\subsection{Improve the CNRCM innovation of efficiency of funding use.}

By changing the efficiency of government administrative functions, raising funds to raise and use efficiency, the limited new rural cooperative funds will be used to solve the problem of farmers' medical security. Gradually establish the new rural cooperative fund audit system, the fund balance of payments, management and other conditions of audit supervision, and timely rectification and correction of problems found in the audit. Overall plan to participate in the establishment of the NPC deputies and CPPCC members and relevant experts to participate in the new rural cooperative supervision committee, the control of agricultural and agricultural funds and management of the situation, the implementation of social supervision.

\subsection{Establish a preventive health care system}

Governments at all levels should attach importance to the development of health industry and adjust measures to local conditions in the construction of prevention and health care system in rural areas. And through the development of health plans to increase the health of farmers consumption, in order to reduce the cost of health care and the total amount of the new rural cooperative medical system.

\section{Acknowledgments}

This article is funded by Zhejiang soft-science research project "Research on health welfare and path choice of farmers in Zhejiang province from the perspective of Rural Revitalization Strategy (Subject number: 2018C35G2150524)", and Hangzhou science and technology project "Research on training path and Countermeasures of Hangzhou's elderly nursing service personnel under the mode of medical maintenance combination (Subject number: 20180533B25)", and Teaching reform project of Medical College of Hangzhou Normal University "The application of diversified teaching mode guided by post trust in the course of health service management -- Taking organizational behavior as an example (Subject number: YXYJG202005)”.

\section{References}

[1] Baldwin, John R., Stephen D. Perry, Mary Anne Moffitt. 2004. Communication Theories, For Everyday Life. Pearson Education, Inc. Boston

[2] Chang Liu. 2014, Reflections on the research of farmer's health under the new rural cooperative medical system. Scientific research management, $\mathbf{3 5}$ (4): 121-129 (In Chinese)

[3] Hiwa Hossaini, Meghdad Pirsaheb , Sheler Khedri. 2015, Evaluation of the environment, health and safety (EH\&S) state of laboratories. International Journal of Health and Life Sciences, 1 (2): 21-27

[4] Holly Wang, Robert Rosenmen. 2007, Perceived Need and Actual Demand for Health Insurance among Rural Chinese Residents. China Economic Review, 18 (December 2007): 373-388

[5] Jin Fen. 2006, China's rural medical consumption behavior's changes and its policy implication. World Economic Forum, 1: 75-88 (In Chinese)

[6] Weizhong Wang. 2008, The implementation of the new rural cooperative medical care and rural residents' income elasticity of demand for medical service in the comparative study. China primary health care, 1: 35-36 (In Chinese)

[7] Wang Hongling. The performance of China's financial support for agriculture from the perspective of increasing farmers' income [J]. Journal of Central University of Finance and economics, 2005 (01): 10-13 (In Chinese)

[8] Xin Gu, Liming Fang. 2006, The public finance system and the new rural cooperative medical funding level of promoting horizontal equalization 
of public services system. Financial Research, 11: 37-46 (In Chinese)

[9] Zhong Wei. 2004, The impact of health on non-agricultural employment and wage determination. Economic Research, 2: 64-73 (In Chinese)

[10] Min Xu, Zhiwen Song, Guang Yang, al. 2007, Constructed wetlands and environmental sanitation safety. Chinese Journal of Ecology, 26 (11): 1873-1877 (In Chinese)

[11] Liping Zhu. 2004, Rationality and sustainability evaluation of financing of new rural cooperative medical system. China health economics, 5: 23-24 (In Chinese)

[12] Shuhong Fu. 2012, The main body interest analysis and model innovation of the CNRCM funding. Agricultural Economy, 2: 109-110 (In Chinese)

[13] Chang Liu. 2012, Review of interdisciplinary research on the mechanism of health and welfare. China health economics, 9: 41-44 (In Chinese)

[14] Lvlin Zhou, et al. 2012, Empirical Study on financing pattern of new rural cooperative medical care system: a case study of Jiangsu. China health service management, 1: 43-46 (In Chinese) 